\title{
Uptake of long-acting reversible contraceptive devices in Western region of The Gambia.
}

\author{
Matthew Anyanwu, ${ }^{1,2}$, Bom Wekye Ndam Alida ${ }^{2}$
}

1. Edward Francis Small Teaching Hospital, Banjul The Gambia

2. School of Medical and Allied Health Sciences, University of The Gambia

\begin{abstract}
Background: The contraceptive method has become an essential factor in the life of most women of reproductive age group; although it varies in different stages of their life course. The use of long acting reversible methods (LARC) is proposed as a strategy to reverse undesirable maternal health consequences in developing countries.

Objective: To determine the uptake of long-acting reversible contraceptive in The Gambia.

Methods: A community based cross-sectional study of women attending family planning clinic were studied using intervieweradministered questionnaire which included information on socio-demographic factors, reproductive health and contraceptive use of the participants.

Results: About $89 \%$ of study participants used long acting reversible contraceptive methods. Of the three commonly available long acting reversible contraceptive methods, Depo Provera was the most commonly used method; 78 of 141 (55.32\%); followed by implants $(43.3 \%)$ and intrauterine contraceptive (1.42\%). Being housewives, with 3-4 living children and having secondary level education were associated with high uptake of LARC.

Conclusion: The uptake of long acting reversible contraceptive was high; with Depo Provera as the most commonly used contraceptive method in The Gambia. There seemed to be an increase in the uptake of implants; with intrauterine contraceptive device being the least commonly used method.
\end{abstract}

Keywords: Uptake, LARC, methods.

DOI: https://dx.doi.org/10.4314/ahs.v17i2.15

Cite as: Anyanwu M, Alida BWN. Uptake of long-acting reversible contraceptive devices in western region of The Gambia. Afri Health Sci. 2017;17(2): 409-417. bttps:// dx.doi.org/10.4314/abs.v17i2.15

\section{Introduction}

The use of contraceptive methods has become an essential factor in the life of most women of reproductive age, although it varies in different stages of their life course. In order to promote women's reproductive health and prevent the risk of unwanted pregnancies, the use of effective contraceptive methods is essential. Long-acting reversible contraceptive methods (LARC) are defined as modern "methods that require administering less than once per cycle or month"1. These include copper intrauterine devices (non-hormonal) and three

\section{Corresponding author:}

Matthew Anyanwu,

Department of Obstetrics and Gynaecology, University of the Gambia School of Medicine and Allied Sciences, P.O. Box 1646, Banjul, The Gambia.

Telephone: +220-9922933, 7786700

E-mail: anyanwum@yahoo.com progestogen-only methods of contraception (Depo-Provera, implants, and Levonorgestral Intrauterine system) ${ }^{1}$. They required skilled health personnel for administration. Efficacy is completely independent of adherence to any chosen method ${ }^{1}$.

The chance of pregnancy over a year of use is significantly lower than short term methods such as pills and barrier methods ${ }^{2}$. LARC is more cost effective with higher continuation rates than short acting contraceptive methods. Therefore, LARC is associated with sustained long-term potential to effectively prevent unwanted births, abortions, dangerous and deleterious effects of pregnancies ${ }^{2}$. The SDG (Sustaining developmental goals) sets two targets for maternal health: to reduce maternal mortality and to achieve universal access to reproductive healthcare. Achieving universal access to reproductive health, including family planning, is much more than a target; it is a means for saving women's lives. The Gambia total fertility rate at $5.6^{3}$ is one of the highest in sub-Sahara Africa and globally, more so, it also has a high maternal mortality ratio of 433 per 100,000 live births ${ }^{3}$. Provision of highly efficacious family planning (FP) services contributes 
to a reduction in maternal mortality by lowering the risk of maternal death per birth hence preventing high-risk and high-parity births ${ }^{4}$. It also offers individuals and couples' ability to anticipate and attain the desired number of children by birth spacing and timing ${ }^{5}$. Use of long acting reversible methods is proposed as a strategy to reverse undesirable maternal health consequences in developing countries $^{6,7}$. Empirical evidence showed that implant and copper-bearing intra-uterine device (IUD) contraceptives are highly effective and well tolerated. Similarly, injectable and implants are proven to be safe, effective and reversible contraceptive options ${ }^{8,9}$.

There is limited data in The Gambia on LARC regarding access and utilization despite established knowledge of availability at little or no cost in most health facilities. Since 1975, FP services have been free of charge and available in all public health sectors in The Gambia. However, the contraceptive prevalence in The Gambia is very low. The Gambia demographic health survey 2013 showed that only $9 \%$ of currently married women use a contraceptive method of any kind, and $8 \%$ use a modern method $^{3}$. The prevalence of modern contraceptive method use in urban areas is three-fold higher than in rural areas (12 percent versus 4 percent, respectively) ${ }^{3}$.

In this study, we investigated the uptake of LARC among women of reproductive age seeking for family planning services at a health facility in the Western region of The Gambia. The factors militating uptake of LARC were also assessed.

\section{Methodology}

Study design: a facility based prospective cross-sectional study.

Eligible study participants were women seeking family planning services during the study period from the $1^{\text {st }}$ of July to the $30^{\text {th }}$ of September 2015 at the Jammeh Foundation for Peace Hospital. It is a health institution that sub-serves over 6000 maternities annually in the heart of Western region of The Gambia.

\section{Data collection}

Interviewer-administered questionnaire was used to collect data for this study. The questionnaire sought information on demographic characteristics, socio-economic status, reproductive history and practice of modern contraception.

\section{Procedure}

We created awareness amongst midwives and nurses who administer family planning services at the health institution. They were also sensitized on the purpose and objectives of the study; and how to administer the questionnaire. The interviewer-administered questionnaire was conducted on consenting consecutive clients as they accessed family planning services until the desired sample size was achieved.

Inclusion and exclusion criteria; women between 1549 years who attended family planning clinic at the health facility from $1^{\text {st }}$ July to $30^{\text {th }}$ September 2015 . Those who did not give consent were excluded.

\section{Sample size calculation}

The sample size for the study was calculated using the prevalence of contraceptive use in The Gambia (12\% for urban region) from the Gambia Demographic and Health Survey 2013 report. The formula below was used; $\mathrm{n}=\left(\mathrm{Z}^{2} \mathrm{p} \mathrm{q}\right) / \mathrm{d}^{2} \mathrm{n}$ is minimum sample size. $\mathrm{Z}$ is the standard normal deviation usually set at 1.96 . $\mathrm{P}$ is the prevalence of contraceptive use in the region (0.12 in urban), $\mathrm{q}$ is $1-\mathrm{p}$ (0.88 in urban,). The degree of accuracy set at 0.05 . The sample size was approximately 160 women of reproductive age.

\section{Statistical analysis}

After all the necessary data was collected, the data was coded on pre-arranged coding sheets by the principal investigator. Data entry and cleaning was done using Epidata version 7 statistical software. Descriptive analysis was used to describe the study sample. The results were presented in tables and figures.

\section{Ethical consideration}

The proposal for the research was submitted and defended at the research committee of the school of medicine and allied health sciences whereby permission was granted to conduct the research. A written letter of consent was submitted to the health institution to seek permission to conduct this study and it was granted. Privacy and confidentiality of clients' information were observed through the use of data collection tool with coded identification numbers. Written consent was obtained from clients who were willing to take part in the study. 


\section{Results}

Socio-demographic characteristics of study participants

The population was predominantly made up of women above the age of 25 years. The majority, $51(40 \%)$ of the women in the 25-29 age group were using long acting reversible contraceptives. The median age of 27 (IQR \pm 5 ).
Almost all, 133 (93.7\%) respondents were Muslim and Christians were nine (6.4\%). Regarding marital status of the women, $124(88.3 \%)$ were married and educational status of participants; majority, $64(45.1 \%)$ had secondary education. Majority, $84(59.2 \%)$ were housewives, 4 $(2.5 \%)$ had no jobs. Whereas for their Husband/partner's occupation; majority, $57(46 \%)$ were civil servants. (Table1)

Table 1 above showed the Socio- demographic characteristics of study participants

\begin{tabular}{|c|c|c|c|}
\hline \multicolumn{2}{|l|}{ Variables } & & \\
\hline $\operatorname{AGE}(\mathrm{n}=160)$ & $\begin{array}{l}15-19 \\
20=24 \\
25-29 \\
30-34 \\
35-39 \\
>40\end{array}$ & $\begin{array}{l}9(5.63 \%) \\
36(22.50 \%) \\
58(36.25 \%) \\
44(27.5 \%) \\
12(7.5 \%) \\
1(0.63 \%)\end{array}$ & $\begin{array}{l}8(5.63 \%) \\
32(22.54 \%) \\
51(39.92 \%) \\
39(27.46 \%) \\
11(7.75 \%) \\
1(0.63 \%)\end{array}$ \\
\hline $\begin{array}{l}\text { Current occupation } \\
(\mathrm{n}=160)\end{array}$ & $\begin{array}{l}\text { House wife } \\
\text { Petty trader } \\
\text { Civil servant } \\
\text { Student } \\
\text { none }\end{array}$ & $\begin{array}{l}96(60 \%) \\
17(10.63 \%) \\
35(21.88 \%) \\
8(5 \%) \\
4(2.50 \%)\end{array}$ & $\begin{array}{l}84(59.15 \%) \\
16(11.27 \%) \\
30(21.13 \%) \\
8(5.63 \%) \\
4(2.82 \%)\end{array}$ \\
\hline $\begin{array}{l}\text { Educational status } \\
(\mathrm{n}=160)\end{array}$ & $\begin{array}{l}\text { Non formal } \\
\text { Primary school } \\
\text { Secondary school } \\
\text { College and above }\end{array}$ & \begin{tabular}{|l}
$56(35 \%)$ \\
$24(15 \%)$ \\
$75(46.88 \%)$ \\
\\
$5(3.13 \%)$
\end{tabular} & $\begin{array}{l}54(38.03 \%) \\
19(13.38 \% 0 \\
64(45.07) \\
\\
5(3.52 \%)\end{array}$ \\
\hline $\begin{array}{l}\text { Marital status } \\
(\mathrm{n}=160)\end{array}$ & $\begin{array}{l}\text { Married } \\
\text { Single } \\
\text { Divorced } \\
\text { Widowed }\end{array}$ & $\begin{array}{l}142(88.75 \%) \\
15(9.38 \%) \\
2(1.25 \%) \\
1(0.63 \%)\end{array}$ & $\begin{array}{l}124(87.32 \%) \\
15(10.56 \%) \\
2(1.41 \%) \\
1(0.79)\end{array}$ \\
\hline Occupation of husband(n=142) & $\begin{array}{l}\text { Farmer } \\
\text { Petty trader } \\
\text { Civil servant } \\
\text { International business } \\
\text { Skilled Trade }\end{array}$ & $\begin{array}{l}13(9.15 \%) \\
41(38.87 \% 0 \\
64(45.07 \%) \\
9(6.34 \%) \\
15(10.56)\end{array}$ & $\begin{array}{l}13(10.48 \%) \\
34(27.42 \%) \\
57(45.92 \%) \\
8(6.45 \%) \\
\\
12(9.68 \%)\end{array}$ \\
\hline Religion(n=160) & $\begin{array}{l}\text { Muslim } \\
\text { Christian }\end{array}$ & $\begin{array}{l}151(94.38 \%) \\
9(5.63 \%)\end{array}$ & $\begin{array}{l}133(93.66 \%) \\
133(93.66 \%)\end{array}$ \\
\hline
\end{tabular}




\section{Reproductive history}

All the women in this study had given birth to a child. Fifty seven $(40.41 \%)$ had three to four live births and one $(0.8 \%)$ did not have live birth. One hundred and twenty four $(87.32 \%)$ never had an abortion. Currently, 58 (41\%) had three to four children. Majority, 71 (57.3\%) had birth interval between their last two children less than two years, and $53(42.74 \%)$ had birth interval above two years. Regarding age of last child of participants, $59(42 \%)$ had a child less than one year. (Table 2 )

Table 2 below described the Frequency and distribution pattern of study participants using long acting reversible contraceptive methods on reproductive variables

\begin{tabular}{|c|c|c|c|}
\hline \multicolumn{2}{|l|}{ Reproductive history } & \multirow{2}{*}{$\begin{array}{l}\text { Frequency } \\
160(100 \%)\end{array}$} & \multirow{2}{*}{\begin{tabular}{|l} 
Percentage (\%) \\
$142(100 \%)$
\end{tabular}} \\
\hline $\begin{array}{l}\text { have you ever given birht to a child } \\
(\mathrm{n}=160)\end{array}$ & Yes & & \\
\hline Number of live births & $\begin{array}{l}0 \\
1-2 \\
3-4 \\
5 \text { and above }\end{array}$ & $\begin{array}{l}1\left(0.63^{\circ} \%\right) \\
54(33.75) \\
65(40.63) \\
40(25 \%)\end{array}$ & $\begin{array}{l}48(3.3 .80 \%) \\
57(40.14 \%) \\
37(26.06 \% \%)\end{array}$ \\
\hline Number of abortions & $\begin{array}{l}0 \\
1 \\
2 \text { and above }\end{array}$ & $\begin{array}{l}14(89.24 \% \%) \\
13(2.23 \%) \\
4(2.53 \%)\end{array}$ & $\begin{array}{l}124(87.32 \%) \\
13(9.15 \%) \\
3\left(2.111^{\circ}\right)\end{array}$ \\
\hline Number of children still lalive & $\begin{array}{l}0 \\
1-2 \\
3.4 \\
5 \text { and above }\end{array}$ & $\begin{array}{l}1\left(0.63^{\circ} \%\right) \\
55(34.38 \% \%) \\
66(41.25 \%) \\
38\left(23.75^{\circ} \%\right)\end{array}$ & $\begin{array}{l}49(3.5 .5 \% \%) \\
58(40.55 \%) \\
35(24.64 \%)\end{array}$ \\
\hline Birth interval between your last two children & $\begin{array}{l}<2 \text { years } \\
2 \text { and above }\end{array}$ & $\begin{array}{l}78(55.71 \%) \\
62(4.29 \%)\end{array}$ & $\begin{array}{l}71(5.26 \%) \\
53(42.74 \%)\end{array}$ \\
\hline Age of hast child & $\begin{array}{l}\text { <year } \\
\text { 1-2year } \\
\text { 3and above }\end{array}$ & $\begin{array}{l}66(41.25 \%) \\
60(37.5 \%) \\
34(21.25 \%)\end{array}$ & $\begin{array}{l}59(1.55 \%) \\
53(7.32 .3 \%) \\
30(21.13)\end{array}$ \\
\hline
\end{tabular}

\section{Family planning information}

The family planning information on the study participants is summarized in Table 3. The major source of information about contraceptive methods was from health care providers accounting for 91 (64.1\%). Majority, 138 $(99 \%)$ of the study participants were able to identify government health facilities as their source of family planning. Most, of the participants, $66(46.81 \%)$ were using 
contraceptives for the first time. Twenty one $(15 \%)$ have been using contraceptives for less than a year, 38 (27\%) had been using contraceptives between one to three years and $16(11.4 \%)$, had been using contraceptive for greater than three years. One hundred and thirty participants $(92.20 \%)$ were using their first method of choice. Ninety four $(66.20 \%)$ of the study participants used contracep- tives for spacing of their deliveries whilst 48 (34\%) was for limiting family size. All the study participants using long acting reversible contraception were satisfied with the modern contraceptive methods available at their source of family planning. Of the participants that had used contraceptive before, majority $(80 \%)$ had used injectable.

\section{Table 3. The frequency and distribution of study participants on family planning information}

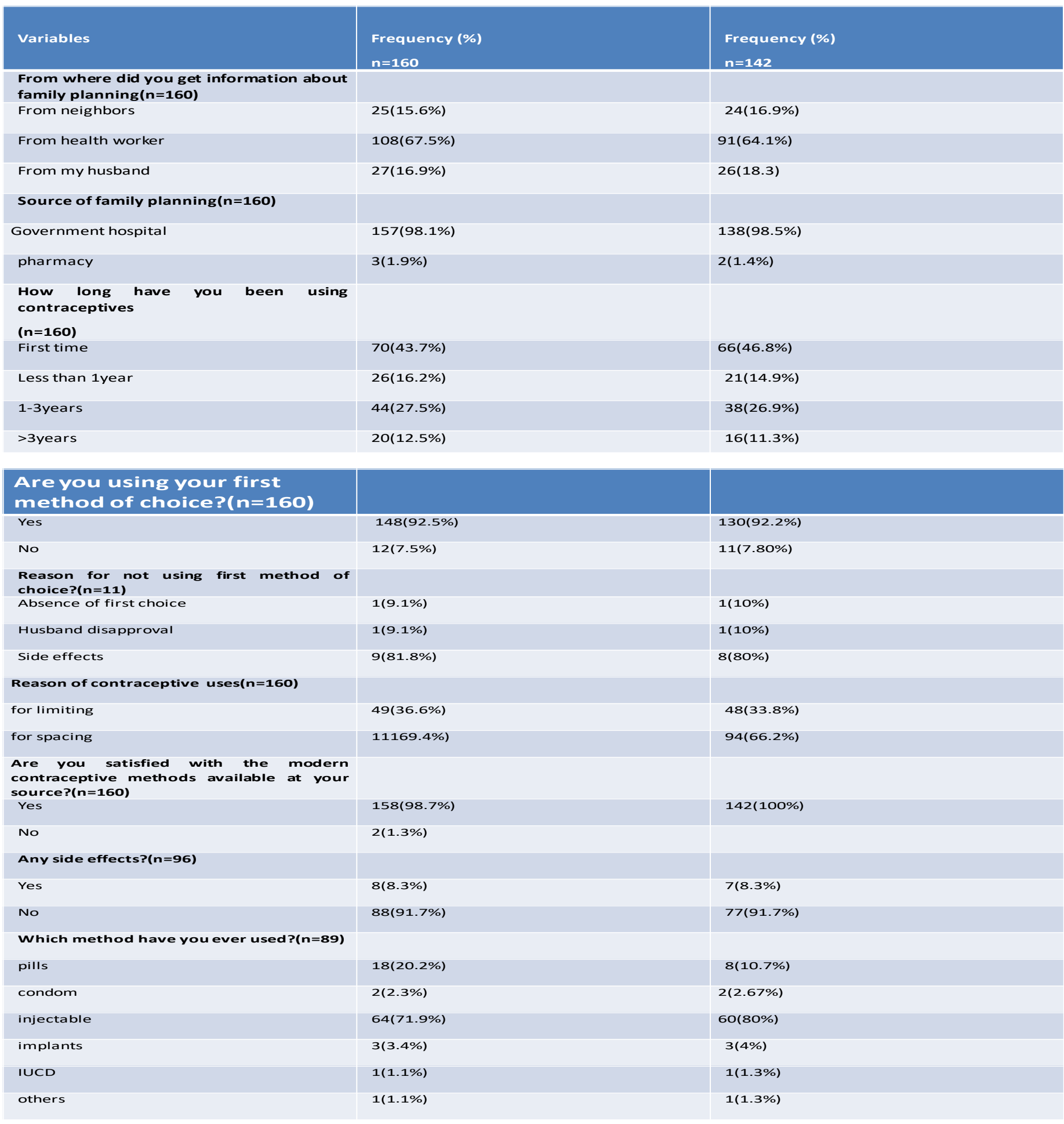


The uptake of long acting reversible contraceptive at the health facility

About $89 \%$ of the women from the sample population who attended family planning clinic at the health facility during the period under review were using long acting reversible contraceptive method.
Of the three long acting reversible contraceptive methods, Depo Provera was the most commonly used method $(55.32 \%)$. The second most used method was implants $(43.3 \%)$.The intrauterine contraceptive device had the lowest percentage of usage among the long acting contraceptive methods $(1.42 \%)$. (Table 4 )

Table 4. Frequency and percentage distribution of respondents on the uptake of long acting reversible contraceptive methods

\begin{tabular}{|l|l|l|}
\hline TYPE OF LARC & Frequency & Percent \\
\hline Depo Provera & 78 & $55.3 \%$ \\
\hline implants & 61 & $43.3 \%$ \\
\hline IUCD & 2 & $1.4 \%$ \\
\hline Total & & $100.00 \%$ \\
\hline
\end{tabular}

\section{Discussion}

This study examined the uptake of long acting reversible contraception among family planning users at the Western region of The Gambia. The study shows that $88.7 \%$ of the study participants were using long acting contraception. This is significantly different from a similar study in Malawi ${ }^{11}$ where the uptake of long acting reversible contraception was $26 \%$. This high discrepancy may be due to the fact that the study design in this study was a single facility based cross sectional study with a small sample size (160) compared to the study in Malawi which was a national representative cross sectional study with a very large sample size $(17,744)$. In this current study, of the three long acting reversible contraceptive methods, the injectable Depo Provera (55.3\%) was the most commonly used with second most used method being implants (43.3\%), the intrauterine contraceptive device had the lowest percentage $(1.4 \%)$ of usage. This result is similar to a study on factors influencing long acting reversible contraceptive use in Malawi ${ }^{11}$, which showed that of the three long acting reversible contraceptive methods, the injectable called Depo Provera was the most commonly used method (24\%) and intrauterine contraceptive devices had the lowest percentage of usage among the long acting reversible contraceptive methods. This is not in line with findings in the study done in NorthWest Ethiopia $^{12}$, of which the, implant $(8.2 \%)$ was the most commonly used and intrauterine contraceptive devices had the lowest percentage (1\%) of usage. This difference is as a result of the fact that their definition of long acting reversible contraceptive methods did not include Depo Provera. It was defined as a short acting contraceptive method. 
Uptake of long acting reversible contraceptives among women of reproductive age is believed to be influenced by a complex interaction of many factors at individual, social and reproductive health service delivery levels. Age, parity and education do influence uptake of modern contraceptives. Cultural norms, marital status, partner/ family support, designated gender roles and the demand for bigger families influence the individual's conception choices ${ }^{11}$. According to this study, the majority (40\%) of women using long acting reversible contraceptives were between the age group 25-29years. This could be because majority, of women in The Gambia were in the age group 25-29 (women weighted number and percentage was 1822 and $17.8 \%$ respectively). Also the age-specific fertility rates start relatively low among women aged 15-19 (88 per 1,000), rise to a peak among women aged 25-29 (271 per 1,000), remain high for women aged 30-34 (237 per 1,000), and decline rapidly at older ages ${ }^{3}$. The result is similar to other studies done in NorthWest Ethiopia ${ }^{12,13}$.

It is established that education influences the uptake of modern contraception among women in Sub-Saharan Africa ${ }^{14}$. This is in line with the findings of this study in which majority (45.1\%) had secondary level of education and the lowest percentage $(3.5 \%)$ were those with college education, this is not surprising considering the report of Gambian Demographic health Survey 2013, the percentage $(32.4 \%)$ of women who had secondary level of education was three times higher $(9.8 \%)$ than those with primary level of education. This findings is similar to other studies done in Ethiopia ${ }^{12}$, Ghana ${ }^{16}$, and Malawi ${ }^{11}$ but is not in line with findings from scholars like Glasier, et al. ${ }^{15}$, Kavanaugh et al. ${ }^{17}$ and Finer, et $\mathrm{al}^{18}$, who indicated that women with a college education were more likely to use long acting reversible contraceptive methods due to their increased knowledge on modern contraceptives.

With regards to occupation of the respondents, about 84 $(89.7 \%)$ were housewives and $57(45.92 \%)$ were civil servants. This was similar to a study in Ethiopia ${ }^{12}$ where the majority of respondents $235(45.3 \%)$ were housewives and their husbands 219(42.2\%) were government employees. Currently the study shows that respondents with more than three children were more likely to use long acting contraceptive which was in line with results of Gambian demographic health survey ${ }^{3}$, in which majority $(10.3 \%)$ of respondents had more than five children still alive. The result was similar to studies done in Ethiopia ${ }^{12}$, Uganda $^{13}$, Ghana ${ }^{16,19}$.

Child spacing $(66.2 \%)$ was the main reason of use of long acting reversible contraceptives in this study which is in line with studies done in Ethiopia ${ }^{12}$, Ghana ${ }^{16,19}$.

Whereas limiting of family size had a lower percentage $(33.8 \%)$.This is in line with The Gambian Demographic Health Survey, the desire to limit fertility markedly increases with the number of living children. The percentage of women that do not want any more children increases from $1 \%$ among women that have only one child to $46 \%$ among women with six or more children. However, the fact that more than $40 \%$ of married women with six or more children still want another child ( $9 \%$ of them soon and $32 \%$ of them later), underscores the preference for large families among Gambian women ${ }^{3}$.

\section{Limitations}

It was a single institution based study conducted only in one region, it might undermine generalization of result to the entire population including rural community and none users.

Healthcare providers' prescribing practice is regarded as one of the main factors which influence women's use of long-acting reversible contraceptives. However, this variable was not assessed in this study.

\section{Conclusion}

The aim of the study was to determine the uptake of long acting reversible contraceptive at a community based health facility in the Western Region of The Gambia which was $89 \%$. The study showed that Depo Provera was the most commonly used contraceptive method in The Gambia.

Among several factors that would affect use of long acting reversible contraceptive methods, age of women, occupation of the respondents, marital status, number of living children were found as determinants of use of long acting reversible contraceptive methods. The use of long acting reversible contraceptive methods is very low among women aged 15-19, gradually increases, and then decreases again toward the end of the reproductive years. Respondents who have the highest percentage of long acting reversible contraceptive method use were house wives, with 3-4 living children, having attained secondary level education. 


\section{Recommendations}

The government should continue to promote education of women since formal education especially significantly increases uptake of long acting reversible contraceptive methods. Secondly governmental and non-governmental organizations, health facilities and other stakeholders need to ensure availability, accessibility and sustained advocacy for use of available contraceptive methods for married couples. In order to win more clients, there is need for a continuous dialogue on the various contraceptive methods between service providers and clients so as to allay some of the clients' fears about supposed side effects of contraception. Lastly, researchers should investigate husbands' perception and acceptance toward contraceptive use by their couples.

\section{Authors' contributions}

MA, BA conceived the idea of the study and participated in its design. BA administered the questionnaires and entered the data into a dedicated database. BA took part in data cleaning and analysis. MA wrote the first draft of the manuscript. Both authors read and approved the final manuscript.

\section{Acknowledgements}

We would like to acknowledge the family planning clinic of Jammeh Foundation for peace hospital and entire staff and management of the institution for acceptance and support demonstrated during the study period. Also we are grateful to the ethics committee for granting us support and approval of the study respectively.

\section{Disclosure of interests}

The authors declare no conflict of interest.

\section{Reference}

1. National Collaborating Centre for Women's and Children's Health Commissioned by the National Institute for Health and Clinical Excellence (NICE; update) 2013.

2. Saleamlak A Y, Berihun M Z, Alemayehu ST. Demand for long acting contraceptive methods and associated factors among family planning service users, Northwest Ethiopia: BMC Research Notes; 2015, 8:29

3. The Republic of Gambia. National Demographic and Health Survey: Gambia Bureau of Statistics Banjul; Ministry of Interior, September 2014.
4. Stover J, Ross J: How increased contraceptive Use has reduced maternal mortality. Maternal Child Health J 2010, 14(5):687-695

5. WHO family planning fact sheet No 351. WHO web site who.int/mediacentre/factsheets/fs351/en update May 2015. Accessed May 2016.

6. UN: Contraceptive Commodities for Women's Health, in Key Data and Findings. New York: United Nations Commission on Life-Saving Commodities for Women and Children; 2012:1-29.

7. UNFPA: United Nations High Level Meeting on Reproductive Health Commodity Security. New York: United Nations; 2011:1-40.

8. Mitchel MT, Thistle P: Acceptability of levonorgestrel, subdermal implants versus tubal ligation for long-term contraception in a rural population of Zimbabwe. Contraception 2004, 70(6):483-486. PubMed

9. Masters T, Everett S: Intrauterine and barrier contraception (a practical review of recent developments). Current Obstetrics Gynecology 2005, 15(1):31-37.

10. Jammeh SS, Chieh-Yu L, Su-Fen C, Jane L-H. Community based study on married couples' family planning knowledge, attitude and practice in rural and urban Gambia; Afr Health Sci. 2014 Jun; 14(2): 273-280.

11. Nyambo Violet: factors influencing long acting reversible contractive use in Malawi, School of Social Science, University of the Witwatersrand, Johannesburg. 2013.

12. Saleamlak A Y, Berihun M Z, Alemayehu ST. Demand for long acting contraceptive methods and associated factors among family planning service users, Northwest Ethiopia: BMC Research Notes; 2015, 8:29

13. Susan Babirye Kayongo: uptake of modern contraception among youths (15-24) at community level in busia district, Uganda, 2013.

14. Blumenthal P, Shah N, Jain K, Saunders A, Clements C, Luca B. et. al. Revitalizing long-acting reversible contraceptives in settings with high unmet need: a multicounty experience matching demand creation and service delivery. Contraception; 2012, 87(2):170-5.

15. Glasier A, Scorer J, Bigrigg A. Attitudes of women in Scotland to contraception: a qualitative study to explore the acceptability of long-acting methods, Journal of Family Planningand Reproductive Health Care 2008; 34(4): 213-218. 16. Adanu, R., Seffah, J., Hill. Contraceptive Use by Women in Accra, Ghana: Results from the 2003 Accra Wom- 
en's Health survey. African Journal of Reproductive Health, (2009). 13(1); 123-133

17. Kavanaugh M, Jerman, J, Hubacher D, Kosk K, Finer L. Characteristics of women in the United States who use Long acting Reversible Contraceptives. Obstetrics and Gynecology. 2011, 117(6): 1349-57

18. Creanga, A, Gillespie, P, Karklins, S, Tsui A. Low
Use of Contraception among Poor Women in Africa: An Equity issue. Bulletin World Health Organisation; 2011, 89:258-266.

19. Okletey M: family planning method choice among married women in the Gomoa west district. University of Ghana, 2007; Web site: : http://hdl.handle. net/123456789/5853. Accessed May 2016. 